\title{
Numerical simulations of semi-armor-piercing warhead penetrating aircraft carrier target
}

\author{
Dong Sangqaing ${ }^{1, a}$, Cai Xinghui ${ }^{1}$, Wang Guoliang ${ }^{1}$, Gao Yunliang ${ }^{1}$, Lu Jiangren ${ }^{1}$ \\ ${ }^{1}$ Xi'an Research Inst. of Hi-Tech in Hongqing Town, Xi'an, P.R. China
}

\begin{abstract}
FEM models of semi-armor-piercing warhead penetrating aircraft carrier deck are established, which are validated by related experimental data. Base on the models, the process of semi-armor-piercing warhead penetrating aircraft carrier deck with different incidence angles and attack angles are carried out. The results show that incidence angles have no remarkable influence on penetration capability of the projectile under the circumstance of zero attack angle. Ductility reaming damage mode and adiabatic plugging damage mode are exhibited in the penetration process. Attack angles have notable influence on penetration capability of the projectile. The FEM models and the results could provide reference for penetration effect research of semi-armor-piercing warhead penetrating aircraft carrier target.
\end{abstract}

\section{Introduction}

As an effective anti-ship weapon, semi-armorpiercing warhead has attained important application in military [1]. Numerical simulation is an important study method in high velocity impact, which needs accurate numerical models and material parameters. In this paper FEM models of semi-armor-piercing warhead penetrating aircraft carrier deck are established, which are validated by related experimental data. Base on the models, the process of semi-armor-piercing warhead penetrating aircraft carrier deck with different incidence angles and attack angles are carried out.

\section{Modeling and Validating}

\subsection{Grid Model}

A half grid model of the projectile and the target are established as Fig.1 and Fig.2 showed. The projectile is made up of shell, charge and fuze, which is $16 \mathrm{~kg}$ in weight, $370 \mathrm{~mm}$ in length, and $105 \mathrm{~mm}$ in diameter. The projectile has a truncated oval nose with diameter of $20 \mathrm{~mm}$.

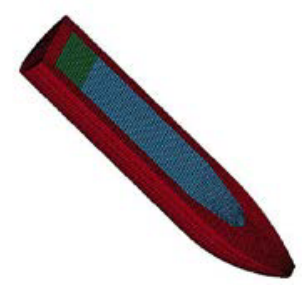

Figure 1. FEM model of the projectile.

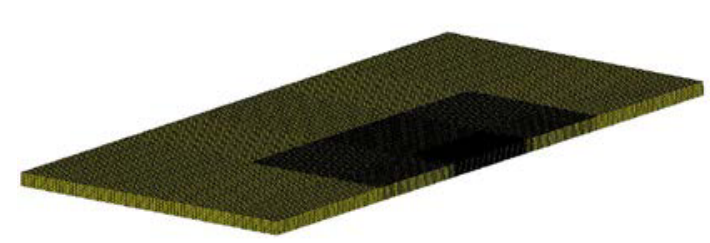

Figure 2. FEM model of the target.

The simplified grid model of the target about "Nimitz-class" aircraft carrier with deck thickness of $50 \mathrm{~mm}$ is created according to the literature [1]. A nonrefection boundary condition is defined to simulate large extent in length.

\subsection{Material models}

According to relative literatures $[2,3]$, materials of the shell and the target are $30 \mathrm{CrMnSi}$ and $921 \mathrm{~A}$ respectively, and the home-produced $9211 \mathrm{~A}$ is equivalent to HY-80 in mechanical performance which is used in the carrier of the U.S. In this numerical simulation model, plastic kinetics model is adopted to describe mechanics behavior of the shell and the target, which considers the effect of strain rate by Cowper-Symonds model,

$$
Y=\left[1+\left(\frac{\varepsilon}{C}\right)^{1 / p}\right]\left(\sigma_{0}+\beta \varepsilon_{e f f}\right)
$$

Where, $\mathrm{Y}$ is yield stress, $\varepsilon$ is strain rate, $\varepsilon_{\text {eff }}$ is effective plastic strain, $\sigma_{0}$ is yield stress in static state, $C$ and $\mathrm{p}$ are material constants, $\beta$ is strength factor, $0 \leq \beta \leq 1$.

\footnotetext{
$\overline{{ }^{a} \text { Corresponding author: shinedsq@ } 126 . c o m}$
} 
The parameters in the model are evaluated according to literatures [2-5], which are listed in Table 1 and Table 2 .

Table 1. Parameters of the shell[2-5].

\begin{tabular}{|c|c|c|c|}
\hline$\rho /\left(\mathrm{kg} / \mathrm{m}^{3}\right)$ & $E /(\mathrm{GPa})$ & $v$ & $\sigma_{0} / \mathrm{MPa}$ \\
\hline 7.85 & 210 & 0.28 & 1600 \\
\hline$E T /(\mathrm{GPa})$ & $C$ & $P$ & $\varepsilon_{\text {eff }}$ \\
\hline 2.1 & 1.0 & 100 & 1.8 \\
\hline
\end{tabular}

Table 2. Parameters of the target [2-5].

\begin{tabular}{|c|c|c|c|}
\hline$\rho /\left(\mathrm{kg} / \mathrm{m}^{3}\right)$ & $E /(\mathrm{GPa})$ & $v$ & $\sigma_{0} / \mathrm{MPa}$ \\
\hline 7.8 & 205 & 0.3 & 685 \\
\hline$E T /(\mathrm{GPa})$ & $C$ & $P$ & $\varepsilon_{\mathrm{eff}}$ \\
\hline 0.19 & 1.0 & 100 & 1.6 \\
\hline
\end{tabular}

The other parts in the projectile are treated as elastic materials, of which the density of the charge and the fuze are $1.7 \mathrm{~g} / \mathrm{cm}^{3}$ and $3.8 \mathrm{~g} / \mathrm{cm}^{3}$ respectively.

\subsection{Model validation}

According to relative literatures [6-8], an FEM validation model is established as shown in Fig.3 and Fig.4, in which the projectile and material models are same with ones described above, and the target is ribbingstiffened and homogeneous with multi-layered space structure.

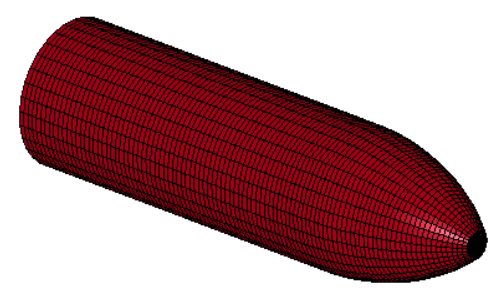

Figure 3. FEM validation model of the target.

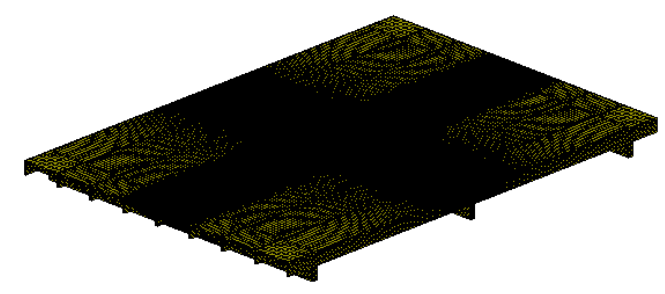

Figure 4. FEM validation model of the target.

With the model, three-dimensionally numerical simulations are carried out by LS-DYNA to analyze nine instances of the projectile impacting the target with different incidence angles. The results show that maximal errors and average errors of calculated values of residual velocity relative to experimental results described in literatures [6] are respectively $6.81 \%$ and $2.37 \%$ for all the nine cases. And that deck damage effects obtained by numerical simulation are in accord with ones in related experiments. The FEM models constructed above are valid and could provide reference for penetration effect research of semi-armor-piercing warhead penetrating aircraft carrier target.

\section{Influence of incidence angles}

\subsection{Penetration capacity}

With the model constructed above, threedimensionally numerical simulations are carried out by LS-DYNA to analyze six instances of the projectile impacting the target with different incidence angles of $0^{\circ}$, $5^{\circ}, 10^{\circ}, 15^{\circ}, 20^{\circ}, 25^{\circ}$ and the same attack angle of $0^{\circ}$. In all the six instances, the initial impact velocity of the projectile is same as $600 \mathrm{~m} / \mathrm{s}$. The time history curves of velocity and acceleration of the projectile in all six instances are given in Fig.5 and Fig. 6 respectively.

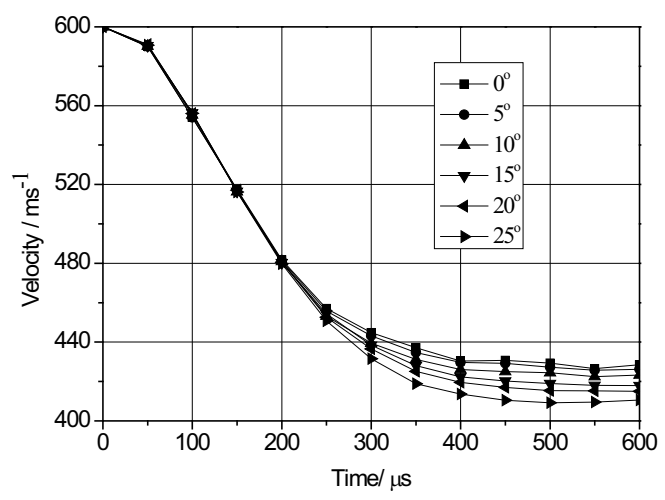

Figure 5. History curves of velocity.

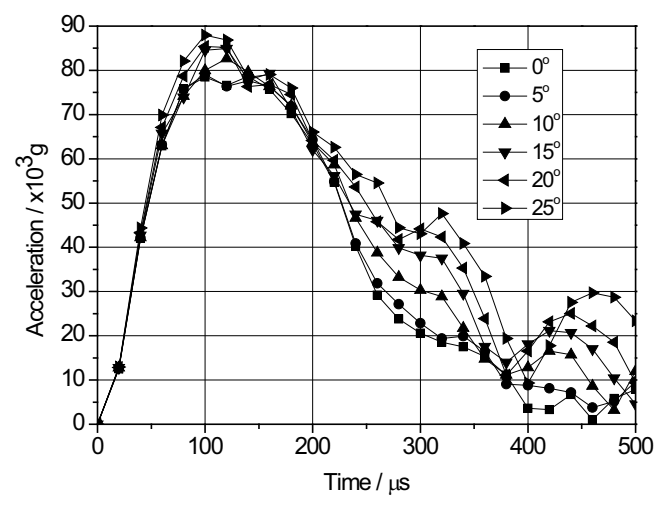

Figure 6. History curves of acceleration.

As shown in Fig.5 and Fig.6, incidence angles have no remarkable influence on residual velocity and maximal acceleration of the projectile under the circumstance of zero attack angles. In all six instances, the values of residual velocity of the projectile are $429 \mathrm{~m} / \mathrm{s}, 426 \mathrm{~m} / \mathrm{s}, 423 \mathrm{~m} / \mathrm{s}, 417 \mathrm{~m} / \mathrm{s}, 415 \mathrm{~m} / \mathrm{s}$ and $411 \mathrm{~m} / \mathrm{s}$ 
respectively, and the values of maximal acceleration of the projectile are $78644 \mathrm{~g}, 79072 \mathrm{~g}, 82664 \mathrm{~g}, 84925 \mathrm{~g}$, $85408 \mathrm{~g}$ and $87980 \mathrm{~g}$ respectively. In the case of the incidence angle of $25^{\circ}$, it is an appreciable decrease of $4.2 \%$ in residual velocity and an appreciable increase of $11.9 \%$ in maximal acceleration compared with the case of the incidence angle of $0^{\circ}$. It can be concluded that incidence angles have no remarkable influence on penetration capability of the projectile under the circumstance of zero attack angles, which are mainly contributed by varying in penetration process which increases with the incidence angle.

\subsection{Damage conformation}

Dynamic response moment of the target and projectile in three instances are given in fig. 5. As shown in Fig.7, the nose of the projectile suffers from serious erosion process as a result of its truncated oval shape and violent interaction with the target, while in whole penetration process of all the six instances the overall structure of the projectile could keep intact with no evident deformation.

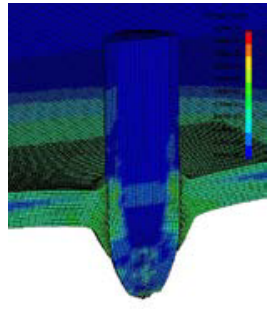

(a) $0^{\circ}$

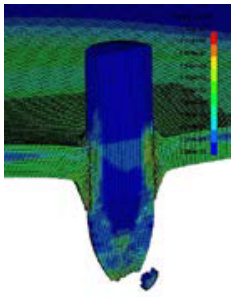

(b) $5^{\circ}$

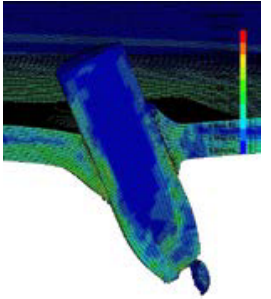

(c) $25^{\circ}$
Figure 7. Dynamic responses of the target.

For the target, ductility reaming damage mode is exhibited in the penetration processes of all the instances. Furthermore when the attack angle is larger than $5^{\circ}$, adiabatic plugging damage mode is exhibited with different size of plugs formed in all other instances, which could be contributed by interaction of compression wave and dilatational wave at the back of the target.

\section{Influence of attack angles}

\subsection{Penetration capacity}

With the FEM established in the paper, threedimensionally numerical simulations are carried out to analyze twelve instances of the projectile impacting the target with six different attack angles, namely $0^{\circ}, 5^{\circ}, 10^{\circ}$, $15^{\circ}, 20^{\circ}$ and $25^{\circ}$, respectively under the conditions of incidence angle of $0^{\circ}$ and $25^{\circ}$. In all the instances the initial velocity of the projectile is $600 \mathrm{~m} / \mathrm{s}$.

When the incidence angle is $0^{\circ}$, as shown in Fig.8, some change in attack angles has notable influence on penetration capability of the projectile. When the attack angel are $5^{\circ}, 10^{\circ}, 15^{\circ}, 20^{\circ}$, and $25^{\circ}$, the values of residual velocity of the projectile decrease $1.7 \%, 7.4 \%, 17.8 \%$,
$34.6 \%$, and $54.5 \%$ respectively relative to the one in attack angle of zero. The residual velocity is $192 \mathrm{~m} / \mathrm{s}$ when the attack angle is $25^{\circ}$.

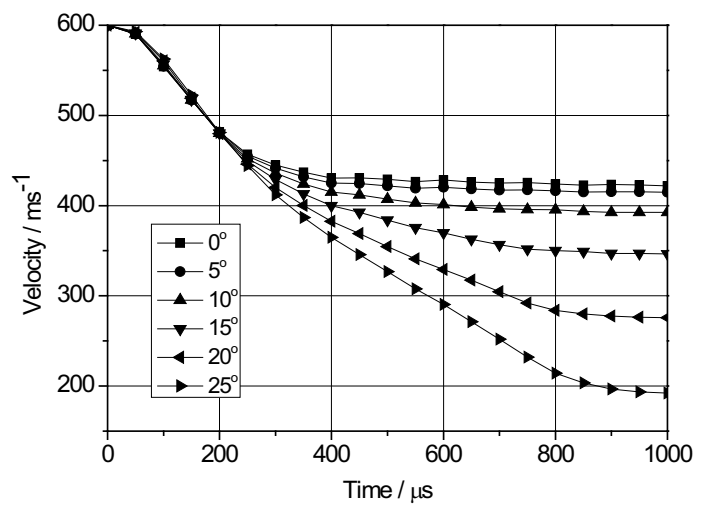

Figure 8. History curves of velocity (incidence angle of $0^{\circ}$ ).

When the incidence angle is $25^{\circ}$, as shown in Fig.9, some change in attack angles has similar influence on penetration capability of the projectile with the case of incidence angle of $0^{\circ}$. When the attack angel are $5^{\circ}, 10^{\circ}$, $15^{\circ}, 20^{\circ}$, and $25^{\circ}$, the values of residual velocity of the projectile decrease $1.5 \%, 7.3 \%, 14.9 \%, 27.3 \%$, and $42 \%$ respectively relative to the one in attack angle of zero. As listed in Table 3 and Table 4, when the attack angle is larger than $15^{\circ}$, the residual velocity has an obvious increase compared with the case of incidence angle of $0^{\circ}$.

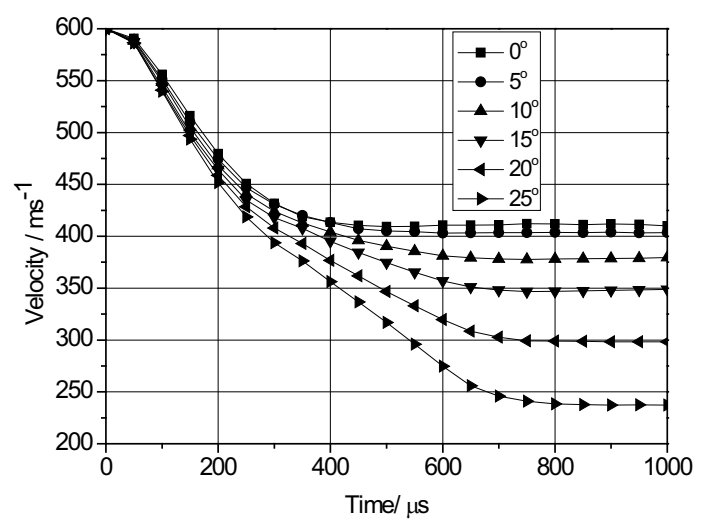

Figure 9. History curves of velocity (incidence angle of $25^{\circ}$ ).

Table 3. The results of incidence angle of $0^{\circ}$.

\begin{tabular}{|c|c|c|}
\hline Attack angle & $\begin{array}{c}\text { residual velocity } \\
/(\mathrm{m} / \mathrm{s})\end{array}$ & $\begin{array}{c}\text { Acceleration } \\
/(\mathrm{g})\end{array}$ \\
\hline $0^{\circ}$ & 422 & 78644 \\
\hline $5^{\mathrm{o}}$ & 415 & 79929 \\
\hline $10^{\mathrm{o}}$ & 393 & 81504 \\
\hline $15^{\mathrm{o}}$ & 347 & 81396 \\
\hline $20^{\mathrm{o}}$ & 276 & 83308 \\
\hline $25^{\circ}$ & 192 & 87683 \\
\hline
\end{tabular}


Table 4. The results of incidence angle of $25^{\circ}$.

\begin{tabular}{|c|c|c|}
\hline Attack angle & $\begin{array}{c}\text { residual velocity } \\
/(\mathrm{m} / \mathrm{s})\end{array}$ & $\begin{array}{c}\text { Acceleration } \\
/(\mathrm{g})\end{array}$ \\
\hline $0^{\mathrm{o}}$ & 410 & 87980 \\
\hline $5^{\mathrm{o}}$ & 404 & 90131 \\
\hline $10^{\mathrm{o}}$ & 380 & 97817 \\
\hline $15^{\mathrm{o}}$ & 349 & 100979 \\
\hline $20^{\circ}$ & 298 & 104197 \\
\hline $25^{\circ}$ & 237 & 107308 \\
\hline
\end{tabular}

As showed in Fig.10, when the incidence-angle is $0^{\circ}$, change in attack angles has no obvious influence on the maximal accelerations. When the attack angle is $25^{\circ}$, the value of maximal accelerations achieved $87683 \mathrm{~g}$, which has an increase of $11.5 \%$ relatively to the one in zero attack angle. While compared with the instance of zero attack-angle, durative high accelerations come forth in the penetration process of other five instances, which maybe lead to serious problems in structure integrity and charge stability.

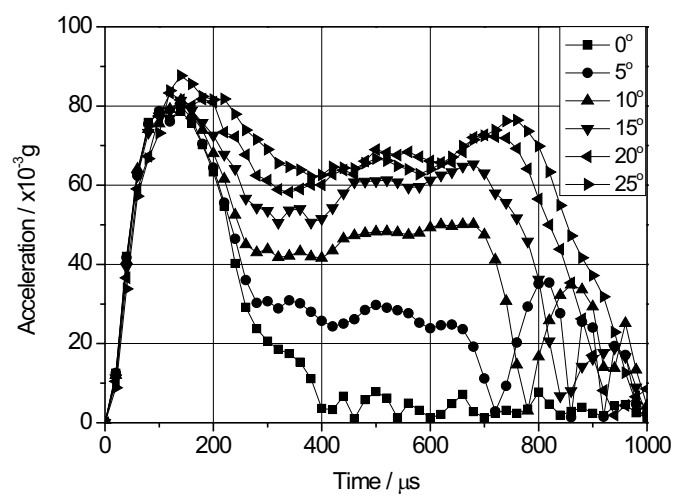

Figure 10. Acceleration curves (incidence angle of $0^{\circ}$ ).

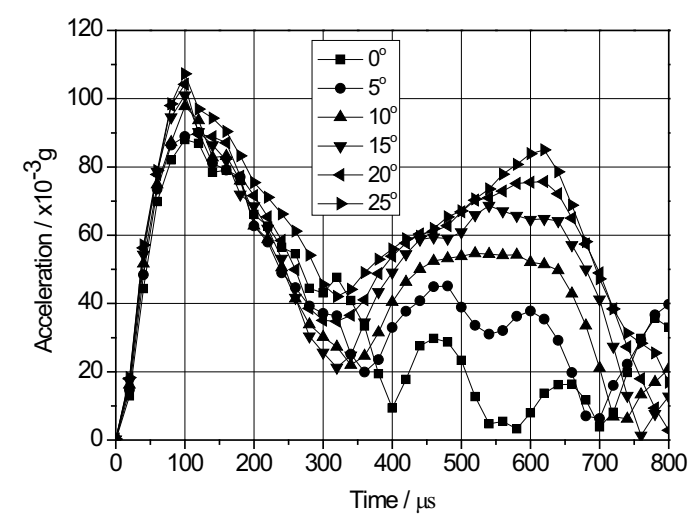

Figure 11. Acceleration curves (incidence angle of $25^{\circ}$ ).

But when the incidence angel is $25^{\circ}$ showed in Fig.11, change in attack angles has evident influence on the maximal accelerations. When the attack angle is $25^{\circ}$, the value of maximal accelerations achieved $107308 \mathrm{~g}$, which has an increase of $22.0 \%$ relatively to the one in zero attack angle. Furthermore as listed in table 3 , for the two different incidence angles, the incidence angel has obvious influence on the maximal accelerations. For the case of $20^{\circ}$ attack angle and $25^{\circ}$ incidence angle the maximal acceleration has a maximal increase of $25.1 \%$ compared with the case of $20^{\circ}$ attack angle and $0^{\circ}$ incidence angle, which can be concluded that when the incidence-angle is $0^{\circ}$ or the attack-angle is $0^{\circ}$, change to some extent of landing posture of the projectile has no obvious influence on the maximal accelerations, but when attack angle and incidence angle both change to some extent, the influence is appreciable.

\subsection{Damage conformation}

Dynamic responses moment of the target and projectile in three instances are given in Fig.12 and Fig.13. Penetration course of the projectile with attack angle of $25^{\circ}$ is given in Fig. 14.

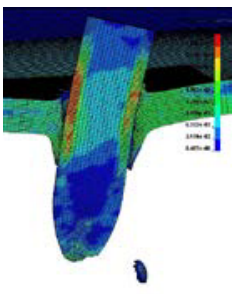

(a) $10^{\circ}$

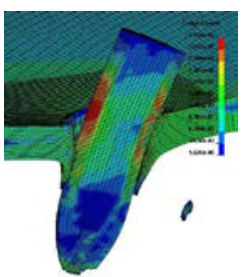

(b) $15^{\circ}$

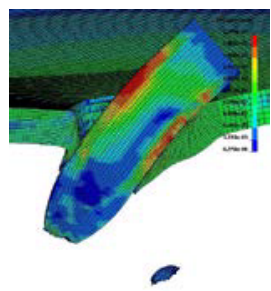

(c) $25^{\circ}$
Figure 12. Dynamic responses ( $0^{\circ}$ incidence angle).
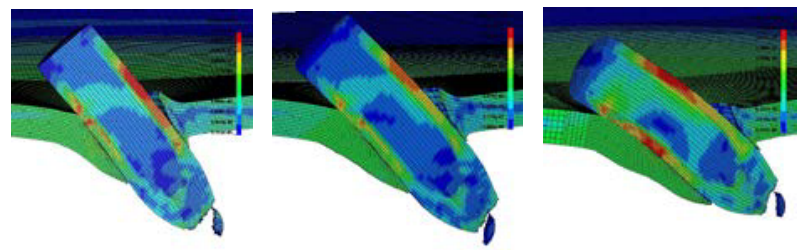

Figure 13. Dynamic responses $\left(25^{\circ}\right.$ incidence angle).

As shown in Fig.12 and Fig.13, the nose of the projectile suffers from serious erosion process as a result of its truncated oval shape and violent interaction with the target. For the target, ductility reaming damage mode is exhibited in the penetration processes of all the instances. Furthermore when the attack angle is larger than $10^{\circ}$, adiabatic plugging damage mode is exhibited with different size of plugs formed at the back of the target in all other instances.

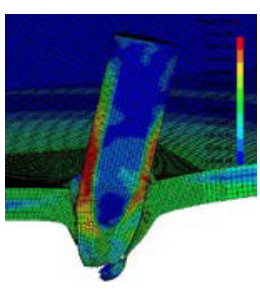

(a) $t=400 \mu \mathrm{s}$

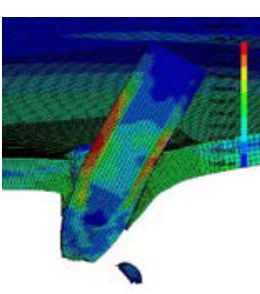

(b) $t=580 \mu \mathrm{s}$

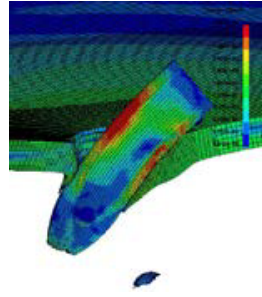

(c) $t=740 \mu \mathrm{s}$
Figure 14. Penetration course of the projectile $\left(25^{\circ}\right.$ attack-angle and $0^{\circ}$ incidence-angle). 
As shown in Fig.14, when the attack angle is equal to $0^{\circ}$, the overall structure of the projectile could keep intact with no evident deformation. While when the attack angle is larger than $5^{\circ}$, the projectile suffer from varying degrees of structure distortion as results of moment loading caused by forces from lateral action, and the structure distortion become serious in extent with increasing of the attack angle. Furthermore, as shown in Fig.5, structure distortion of the projectile suffer from a process of first bending left and subsequently turn right, which could lead to serious risk for the integrity of the projectile structure and the stability of the charge.

\section{Conclusions}

(1) FEM models of semi-armor-piercing warhead penetrating aircraft carrier deck are established by numerical simulation method, which are validated by related experimental data.

(2) Change in attack angles has notable influence on penetration capability of the projectile. When the attack angel are $5^{\circ}, 10^{\circ}, 15^{\circ}, 20^{\circ}$, and $25^{\circ}$, the values of residual velocity of the projectile decrease $1.7 \%, 6.9 \%, 17.8 \%$, $34.6 \%$, and $54.5 \%$ respectively relative to the one in attack angle of zero. Change to some extent in attackangle or incidence-angle has no obvious influence on the maximal accelerations, but when attack angle and incidence angle both change to some extent, the influence is appreciable.

(3) The projectile suffer from varying degrees of structure distortion when the attack angle is larger than $5^{\circ}$ and the structure distortion become serious in extent with increasing of the attack angle. For the case discussed in this paper, it is suitable for the projectile to keep an attack angle of no more than $10^{\circ}$.

\section{References}

1. Lan Ling. Torpedo Technology. 10, 8(2002)

2. Jones N. Structural Impact [M]. (1st Edition, 1989). Paperback Edition Cambridge, Cambridge University Press, 403(1977)

3. LS-DYNA KEYWORD USER'S MANUAL[CP]. March 2003 Version 970

4. Zhang Lin, Zhang Zugen, QIN Xiaoyun, etc. Chinese Journal of High Pressure Physic. 17,305( 2003)

5. Liu Xinde. Aerospace Materials and Technology. 29(1985)

6. Duan Zhuoping. Explosion and Shock Waves. 25,547(2005)

7. Duan Zhuoping, Zhang Zhongguo, Li Jingzhu, etc. Journal of Projectiles, Rockets, Missiles and Guidance. 25,148(2005)

8. Song Weidong, Ning Jianguo, Zhang Zhongguo, etc. Journal of Ballistics. 16,49(2004) 